\title{
Editorial
}

\section{A Look Ahead in a Time of Challenge}

It is common in the face of major events for a publication's editorial to comment on those events and their impact on the primary subject matter of that publication. Accordingly, we must briefly pre-empt our discussion of a major milestone in our journal's history to comment on the COVID-19 pandemic and its potential impact on the broad fields of environmental policy and environmental law.

At this writing, some members of the editorial staff of EPL remain on mandatory or voluntary lockdown, in connection with global and national efforts to combat the spread of the novel coronavirus known generally as "COVID-19". Like the rest of the world, we have read or heard literally hundreds of articles, stories, blogs, tweets, prognostications and rumours about the virus and a long list of guesses about governmental or institutional responses. As lawyers, policy specialists and reporters, we possess no specialised knowledge of these matters. Watching the behaviour of high-level officials in governments around the world, we have come to realise that there is no reliable basis for even guessing at the extent to which the "new normal" that will come into being when the lockdowns end will resemble or impact the most recent normal that we are now so fondly remembering.

Accordingly, EPL cannot and will not join the rank-upon-rank of unqualified commenters adding their views on the pandemic or their prognostications on a very uncertain future. Like all rational people, we are closely following the news and statements of those we find to be credible sources. Among these, we have found the "Open Letter" to the World Health Organization and the UN Environment Programme (printed in this issue at pp 5-15) to be the most rational and credible writing on the environmental impacts that the pandemic will have on global and national environmental policy. It has focused on known issues and common beliefs, emphasising their impacts on the equitable issues that have arisen in discussions with regard to the conservation of biological diversity, providing counsel to world leaders regarding factors that should be considered before adopting popular measures that can have serious negative consequences.

Beyond this, EPL's role is one of sharing scholarship as well as assessing and sharing the practices and measures chosen by each particular country, organisation or community as potential responses to the lessons of the past six months. Even articles and comments that suggest particular approaches or measures, however, cannot and should not be the product of guessing and divination, but will instead involve in-depth professional study and analysis based on an array of data, embodying both experience and statistical understanding. Such articles will arrive at our offices, and be published in our journal over time. We strongly encourage those who are working in or with governments and institutions to help us share your proposals and experiences in regard to the environmental aspects of all changes (economic and social, as well as geophysical) to environmental policy and law, and all areas in which environmental action must accommodate new pandemic responses. In turn, we pledge to provide coverage of international and regional negotiations, programmes and other efforts to address these matters.

Throughout the coming years, EPL commits to remaining aware of issues and developments relating to the pandemic-related developments of environmental policy and law, and to avoiding the trap of seeking to appear "current" by providing inexpert commentary.

We now return you to our originally intended editorial:

With this issue, Environmental Policy and Law opens its $50^{\text {th }}$ volume, a fact worthy of commemoration and a few moments of looking 
back, along with a brief consideration of how EPL will move into its future. When it was founded by the late, great Dr Wolfgang E. Burhenne, EPL was dedicated to fulfilling the function of "developing the exchange of information on legal, administrative and policy aspects of environmental conservation" (Editorial, EPL 1(1) (1975)). ${ }^{1}$ At the time, however, it was clear that "[o]pinions have differed... as to the need for such a journal and what it should be like". EPL needed to be "not quite... a journal, nor.. a magazine, but something of a compromise between the two", with the objective that it "be read and ... useful, and ... keep our readers interested in the materials we present".

Perhaps the most unique aspect of EPL, however, was its target audience. It would not focus on "those who would like to be "well-rounded", but rather address the needs of "a special group of persons who are actively involved with problems of environmental law and policy". This goal stood out because

we do not seek to create a scholarly journal, where experts speak to experts over their common expertise. [Instead] our central purpose is to report and analyze developments, which should be of international interest - to inform those active in the environmental field in one country of the theories and practices being developed in other countries or at the international level.

\section{(Ibid.)}

Overall, the goal of EPL was encapsulated as follows: "[to] serve as a means of communication among decisionmakers around the world" (ibid., emphasis in original). It is this aspect of our role that is discussed in the opening paragraphs of this editorial.

The scope of EPL's coverage was another somewhat unique element at that time. Although it was a period of major development in international environmental law and institutions, EPL was intended to emphasise the local nature of environmental solutions. Hence, it was tasked to address problems and issues at both global and local scales. In particular, there is great value to local and national action in knowing what approach other countries had taken to address similar problems:

[T]he industrialized countries must deal with similar problems of air pollution and rising energy consumption; developing countries confront crises in food production and depletion of natural resources; and virtually all nations are witnessing a more or less rapid urbanization process, which is upsetting many features of the human and natural environment. The experience of one nation in seeking to manage such problems may offer valuable lessons to decision-makers elsewhere. A comparison of the experience of several nations may reveal possibilities for cooperation to the benefit of all.

(Ibid).

Over the ensuing 45 years, EPL has kept faith with these objectives. It has carefully followed and reported on the work of international bodies (the UN General Assembly, UN Environment Programme, UN Development Programme, the Food and Agriculture Organization, etc.) and conventions at global and regional levels. It has provided regular expert coverage of major negotiations by which multilateral environmental agreements have been developed across the range of environmental focus areas: conservation, sustainable development, pollution prevention, energy, natural resources, ecosystem restoration, public awareness/ involvement, definition and regulation of matters beyond national jurisdiction, national cooperation on matters within national sovereignty, and even definition and regulation of new concepts of resource ownership and responsibility (e.g., the CBD's work on "biosafety" and "access and benefit sharing"). When those negotiations were completed and fewer new negotiations were held, EPL's coverage did not diminish; instead it moved on to cover the novel process common to most multilateral environmental agreements - the regular meetings of the States that have become Parties to those conventions and the specialised discussion groups, new programmes and implementation concepts they have sponsored or participated in. Throughout all of these world-changing developments, EPL has endeavoured to keep its focus on the practical aspects of the work being done and the results produced. Its team of reporters and network of contributors have emphasised the needs and interests of the law- and policy-making professionals working in these areas, providing information and insights regarding the deliberations and issues presented, and their impact on the practical work of environmental governance, both in 
governments/institutions and in private-sector bodies.

While EPL has kept a strong focus on international law and policy issues, it has not neglected more local concerns. While some articles published have looked into the work of international bodies and the collaboration of States in achieving shared objectives, most have focused on how national governments have addressed environmental challenges, including how they have learned from the efforts and experiences of other countries. Here also, to the extent possible, EPL has endeavoured to focus on the practical aspects of these issues, giving priority to articles addressing national implementation of environmental solutions, rather than academic or theoretical analyses of these issues.

Perhaps most important, EPL has always attempted to be truly a global publication, continually committed to providing a printed platform for authors from countries not often represented in international legal journals - those whose linguistic or national restrictions may have prevented them from receiving the level of professional exposure their issues deserved. EPL's staff and frequent contributors have included and still include regular contributors from five continents and Oceania, and articles have been submitted for publication from over 70 countries.

Today, of course, EPL is operating in a world very different from that of 1975 . Publication has changed in the wake of the internet revolution. It has, for example, enabled anyone with a connection to observe many international and national events, and to obtain access to their results almost immediately. Some early features of EPL, such as the publication of "Selected Documents" and "References to Other Topics" were discontinued years ago, as surplus in the new world of instant access. The fields of international and comparative environmental law and policy have changed as well, expanding mightily, both in the range of focus areas and in the sheer number of professionals who specialise in these areas. Accordingly, other journals, blogs, portals, webinars and online discussions have been developed in many environmental sub-areas, some of which are also offering the type of informational, practical and professional focus to which EPL has committed.

Some constants still remain, however; in addition to founding EPL, Dr Burhenne was a primary mover in the creation of an important professional organisation - the International Council on Environmental Law (ICEL) - and the impetus that drove its creation still exists. Following his death, ICEL members have gathered and reorganised, and a new ICEL has been established, now headquartered at the University Carlos III of Madrid. Throughout his life, Dr Burhenne promoted a close relationship between ICEL and EPL, and many ICEL members have been valuable contributors to EPL.

All of these factors have combined to bring about further growth of EPL's work and vision. When he died, at age 92, Dr Burhenne was not a fan of change, but even then he would instantly take an active interest in the evolution of EPL to adapt it to modern times and, to the end, continued to ascribe to the goal stated in his first editorial: "Environmental Policy and Law is somewhat of an experiment, aimed to determine whether the sort of communicative effort envisioned will find acceptance and prove to be of value".

Accordingly, EPL is continuing to adapt, still with the goal of meeting the needs of working professionals in the full range of fields of environmental law and policy. Some of the first steps in this process are visible in the current issue: the development of a new system of "Online Submission" for articles (including more detailed information on requirements and selection criteria), and the adoption of the new cover and publishing format showcased in this issue.

Substantively, we are more fully embracing the "policy" side of our mandate, beginning intensive efforts to seek out articles that are more "data-driven" and to support the international goals of "science-based" and "fact-based" environmental action by demonstrating the facts underlying calls for action.

Towards that end, we have begun an intensive push to expand the membership of EPL's Editorial Board. Over the years, its current members have shown themselves to be deeply committed to EPL's goals and vision, for which we are grateful. We note, however, that the Board has slowly self-evolved into a body consisting primarily of environmental law academics (a group the editor likes, being now a part of it), with fewer practical law/policy experts and greater unanimity of viewpoint on basic environmental issues. Board expansion is intended to remedy this status quo without eliminating our long-time members, by adding new voices and perspectives, including a 
strong emphasis on scientific policy contributions, especially statistical bodies. In this process, we are also guided again by our original vision:

We see this journal as a contribution to the cause of environmental protection. Nonetheless, we do not intend to publish only material which appears to be "pro-environment". Perceptive attacks on environmentalist efforts and well-reasoned defences of "anti-environmental" policies will find space in EPL. Those who would defend the environment might then be prepared to reply, and also to rethink their positions, if necessary.

\section{(Ibid.)}

While our Board membership criteria continue to insist that members be eminent and expert in environmental law/policy fields, we are attempting to ensure that all views and positions on environmental issues be reflected, and that the Board's membership reflects a more balanced coverage of environmental policy and environmental law.

Thus, with nearly a half century of experience, and a continuing respect for our founder - one of the luminaries of environmental law - EPL will continue to grow, evolve and prepare to fill an enduring role in a new future of environmental law and policy around the world.

Tomme R. Young

Managing Editor, Environmental Policy and Law

\section{Endnotes}

\footnotetext{
${ }^{1}$ During the first five years of its existence, EPL published two volumes per year.
} 